\title{
EFFECTS OF SUDARSHAN KRIYA ON STRESS REDUCTION IN GENERAL POPULATION
}

\author{
Rajeshree Tukaram Patil1, Rajendra Tukaram Patil2, Suresh Narayanrao Ughade3, Manjusha Sureshchandra Hatwar ${ }^{4}$
}

1Associate Professor, Department of Obstetrics and Gynaecology, GMC Gondia, Nagpur, Maharashtra, India.

${ }^{2}$ Consultant and Ex-Associate Professor, Department of Orthopaedics, IGGMC, Nagpur, Maharashtra, India.

${ }_{3}^{3}$ Biostatistician (Associate Professor), Department of Community Medicine, GMC, Nagpur, Maharashtra, India.

${ }^{4}$ Health Care Management, Dhantoli, Nagpur, Maharashtra, India.

\begin{abstract}
BACKGROUND

Stress, depression and anxiety have a yearly prevalence of 10 to $20 \%$ in the general population. All factors that cause one's conditions to diverge too far from the normal homeostasis lead to stress. Our attempts to restore the condition back to homeostasis also leads to stress. Stress affects quality of life by affecting the factors like level of unhappiness, focus, sleep disturbances, anger, frustration etc., because while responding to stress the sympathetic nervous system becomes active. Asthma, headache, IBS, anxiety and ulcers are the commonest presentations in stressful people. Various methods are studied in literature to relieve stress like exercise, walking, pranayam, meditation, gym, music and games. Sudarshan Kriya (SK) claims to have wide and varied effects on human body in different aspects. SK stimulates vagal response and counterbalances the effects of stress.
\end{abstract}

\section{MATERIALS AND METHODS}

This is a cohort study with group comparison of subjects regularly practicing SK for more than 6 months. Age matched controls used other Stress Releasing Measure (SRM) like walking, pranayam and gym with ethical standards. Data collection was done by close-ended questionnaire using Likert score for comparison of parameters.

Statistical Analysis- The data were entered into the computer and analysed by using the Statistical Package for Social Sciences (SPSS) version 10.0 programs for Windows. Unpaired student's t-test, the mean and SD was calculated. The significant value was achieved at $\mathrm{p}<0.05$.

\section{RESULTS}

The selected population faced equal challenges in life. Stress created equal impact in the controls and study subjects. Although, the controls have shown a definite improvement in the quality of life after using stress releasing measures. But, the study shows that controls feel more stressed than SK doers ( $p$ was significant at 0.02). The regular SK doers are more focussed with a positive outlook. Categorically (Qualitatively), there was a significant shift towards Likert score of 5 in the SK doers ( $p=0.002)$. SK doers significantly surpassed the control group by scoring highest on Likert scale in almost every parameter studied, e.g. levels of happiness, focus, sleep patterns, anger, frustration, outlook, habits of consuming alcohol, gutka, tobacco and even medical problems. Thus, life appears eased out in regular kriya doers.

\section{CONCLUSION}

SK relieves stress in general population in a very significant manner when compared with other stress releasing measures. SK has an extremely positive effect on physical and mental health of the general population. It can definitely be recommended as a highly beneficial, no risk, low cost option to take care of stress and its effects on the human body.

\section{KEY WORDS}

Stress, Anxiety, Depression, Sudarshan Kriya, Stress Releasing Measures.

HOW TO CITE THIS ARTICLE: Patil RT, Patil RT, Ughade SN, et al. Effects of sudarshan kriya on stress reduction in general population. J. Evolution Med. Dent. Sci. 2018;7(29):3285-3292, DOI: 10.14260/jemds/2018/740

\section{BACKGROUND}

Stress is a response to a stressor. It is rather a method of reacting to a challenge. Stress, depression and anxiety have a yearly prevalence of 10 to $20 \%$ in the general population. ${ }^{(1)}$ All factors that cause one's condition to diverge too far from the normal homeostasis lead to stress. Our attempts to restore the condition back to homeostasis also leads to stress. In such conditions, the flight/ fight response recruits the

'Financial or Other Competing Interest': None.

Submission 31-01-2018, Peer Review 29-06-2018,

Acceptance 05-07-2018, Published 16-07-2018.

Corresponding Author:

Dr. Rajeshree Tukaram Patil,

Chaitanya, 116A, Behind Chhatrapati Hall,

Chhatrapati Nagar, Nagpur-15,

Maharashtra, India.

E-mail: rajeshree_dr@yahoo.com

DOI: $10.14260 /$ jemds $/ 2018 / 740$

\section{(c) $($ ) $\$$}

energy stores and focuses the attention to overcome the challenges at hand. Stress affects quality of life by affecting the factors like level of unhappiness, focus, sleep disturbances, anger, frustration etc., because while responding to stress the sympathetic nervous system becomes active. Sympathetic nervous system regulates the body's physiological function to make the body adaptive to environment. Brain plays an important role in perceiving the response to stress. Asthma, headache, IBS, anxiety and ulcers are the commonest presentations in stressful people.(2-9) Stress is widely prevalent in all sections/ strata of society. Various methods are studied in literature to relieve stress. Exercise, walking, pranayam, meditation, gym, music, games and Sudarshan Kriya (SK) has a positive effect on physical and mental health. SK claims to have wide and varied effects on human body in different aspects.(8-20) The vagus nerve is the single most relevant organ in our body relative to our peace of mind and happiness. Research indicates that a 
healthy vagus nerve is vital in experiencing empathy and fostering social bonding and it is crucial to our ability to observe, perceive and make complex decisions. Tests have revealed that people with impaired vagal activity have also been diagnosed with depression, panic disorders, posttraumatic stress disorders, irritable bowel syndrome, anxiety and mood swings. The powerful breathing technique that naturally stimulates the vagus nerve is called "The Sudarshan Kriya." Scientists have found that Sudarshan Kriya and Pranayama (SK along with related practices of yogic asanas, pranayama, nadi shodhan and meditation) can be extremely effective in opening up this vital channel of energy.(21)

\section{Hypothesis}

Can Sudarshan Kriya be useful in reducing stress and its effects in general population?

\section{MATERIALS AND METHODS}

This is a cohort study. The procedure followed is in accordance with ethical standards. Informed consent from the study participants was sought. Age matched controls used other Stress Releasing Measure (SRM) like walking, pranayam, gym with ethical standards, data collection done by close ended questionnaire using Likert's score for comparison of parameters. They were selected by convenience sampling technique.

\section{Inclusion Criteria}

Study subjects were people between 20 and 45 yrs., who were exclusively practicing SK regularly for more than 6 months. Controls were age matched persons from the same population who were using other methods of relaxation and health like walking, pranayam, music and gym.

\section{Selection of Controls}

Age matched controls who were routinely and regularly performing other exercises like walking, gym, music, games, meditation and pranayam were selected from the same community/ area for which SK subjects were selected.

\section{Exclusion Criteria}

Persons doing relaxation techniques from a long time, but now having a gap of more than 7 days so that the effects wane off and those who refused consent to participate in the study.

\section{Data Collection}

A close-ended questionnaire using Likert's score was used and information on the study variables, stress parameters and socio-demographics of individual study subjects was recorded.

Data was summarised by mean, Standard Deviation (SD), frequencies and percentages.

A ' $p$ ' value less than 0.05 was considered statistically significant.

\section{Statistical Analysis}

The data were entered into the computer and analysed by using the Statistical Package for Social Sciences (SPSS) version 10.0 programs for Windows. Unpaired student's ttest, the means and SD was calculated. The significance value was achieved at $\mathrm{p}<0.05$.

\section{RESULTS}

When asked "are you happy in life?" SK doers strongly agreed and showed a high Likert's score than the controls. Study by convenient sampling technique since the duration of the study was 6 months. They were selected by convenience sampling technique. The cause of unhappiness was found to be friends/ relatives in the controls, while for SK doers it was one's outlook and own-self ( $\mathrm{p}=0.03$ significant). Both groups agreed that life is a challenge.

Both groups faced challenges equally $(\mathrm{p}=0.77$, nonsignificant), but stress had more impact in controls than in SK doers $(p=0.02)$. Thus, life appears eased out in Kriya doers.

When compared for symptoms due to challenges and stress, stress produced similar symptoms in both the groups (as suggested by non-significant p-value for all symptom parameters, e.g. asthma, headache, IBS, anxiety).

When effects of stress releasing methods were compared in two groups, the results were remarkable in SK doers, as is seen in Table 1 below. A significant reduction in mean stress scores was obtained for most of the parameters, except anger and frustration where quantitative estimation did not show any significant difference.

\begin{tabular}{|c|c|c|c|c|c|c|c|c|}
\hline Stress & $\begin{array}{c}\text { Study } \\
\text { Group } \\
(\mathrm{n}=100)\end{array}$ & & $\begin{array}{c}\text { Control } \\
\text { Group } \\
(n=100)\end{array}$ & & $\begin{array}{l}\text { Difference } \\
\text { in Change }\end{array}$ & & $\begin{array}{c}\text { P- } \\
\text { value }\end{array}$ & $\begin{array}{l}\text { Significance } \\
\text { of Difference }\end{array}$ \\
\hline Symptoms & $\begin{array}{c}\text { Mean } \\
\text { Change }\end{array}$ & $\begin{array}{c}\text { SD } \\
\text { Change }\end{array}$ & $\begin{array}{c}\text { Mean } \\
\text { Change }\end{array}$ & $\begin{array}{c}\text { SD } \\
\text { Change }\end{array}$ & $\begin{array}{c}\text { Mean } \\
\text { Difference }\end{array}$ & $\begin{array}{c}\text { SD } \\
\text { Difference }\end{array}$ & & \\
\hline Levels of Happiness & 1.1 & 1.9 & 0.32 & 1.6 & 0.78 & 1.79 & 0.0019 & $\begin{array}{c}\text { Highly } \\
\text { Significant }\end{array}$ \\
\hline Focus & 1.05 & 1.79 & 0.45 & 1.54 & 0.6 & 1.69 & 0.0118 & Significant \\
\hline Sleep Pattern & 1.05 & 1.99 & 0.27 & 1.54 & 0.78 & 1.82 & 0.0022 & $\begin{array}{l}\text { Highly } \\
\text { Significant }\end{array}$ \\
\hline Frustration & 0.62 & 1.87 & 0.57 & 1.65 & 0.05 & 1.76 & 0.8413 & Not Significant \\
\hline Anger & 0.41 & 2 & 0.23 & 1.87 & 0.18 & 1.93 & 0.5117 & Not Significant \\
\hline Change in Outlook & 1.32 & 1.5 & 0.19 & 1.97 & 1,13 & 1,83 & 0.0001 & $\begin{array}{c}\text { Highly } \\
\text { Significant } \\
\end{array}$ \\
\hline $\begin{array}{c}\text { Consumption of } \\
\text { Alcohol/Tobacco/Cigars }\end{array}$ & 2.99 & 1.18 & 1.92 & 0,79 & 1.07 & 1.14 & 0.0001 & $\begin{array}{c}\text { Highly } \\
\text { Significant } \\
\end{array}$ \\
\hline Medical Problems & 4.32 & 1.67 & 4 & 1,67 & 0.32 & 1.67 & 0.177 & Not Significant \\
\hline
\end{tabular}


However, categorical estimation for all of the study parameters (Table 2 onwards) was found to be significant as follows:

Table 2- Levels of happiness: A significant shift towards Likert's 5 in SK doers $(p=0.002)$. Most of the SK doers are frequently happy now.

\begin{tabular}{|c|c|c|}
\hline Likert's Score & Before SRM & After SRM \\
\hline 1 (never) & 2 & 1 \\
\hline 2 (rarely) & 10 & 3 \\
\hline 3 (occasionally) & 27 & 18 \\
\hline 4 (frequently) & 39 & 50 \\
\hline 5 (very frequently) & 25 & 32 \\
\hline \multicolumn{2}{|c|}{ Table 2(A). Levels of Happiness in Controls (G1) } \\
\hline
\end{tabular}

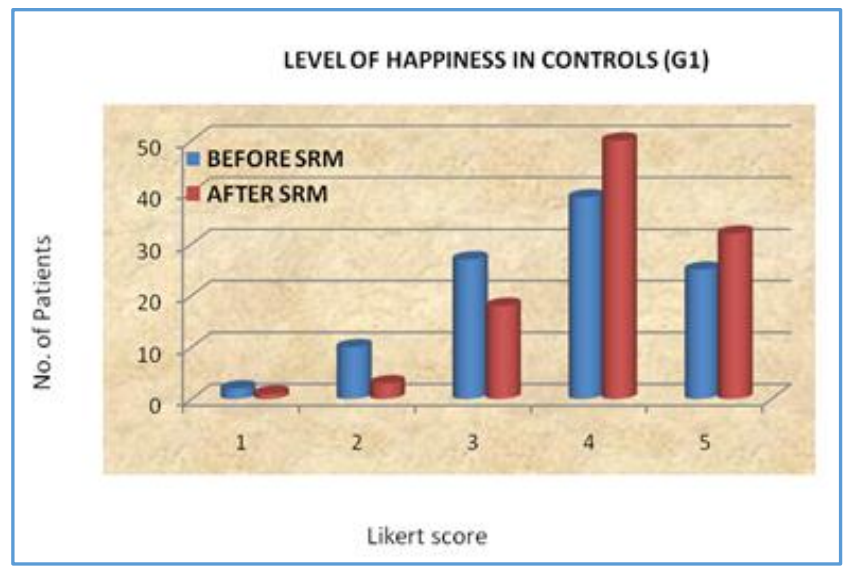

\begin{tabular}{|c|c|c|}
\hline Likert's Score & Before SRM & After SRM \\
\hline 1 (never) & 3 & 0 \\
\hline 2 (rarely) & 19 & 1 \\
\hline 3 (occasionally) & 36 & 8 \\
\hline 4 (frequently) & 25 & 33 \\
\hline 5 (very frequently) & 21 & 62 \\
\hline \multicolumn{2}{|c|}{ Table 2(B). Levels of Happiness in Subjects (G2) } \\
\hline
\end{tabular}

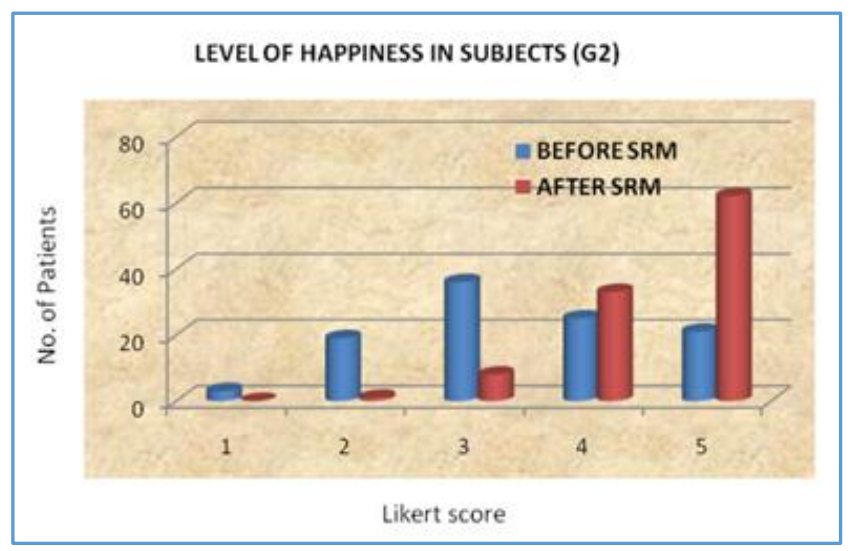

Table 3- Focus: Focus improved significantly when SK was used to relieve stress $(\mathrm{p}=0.03)$.

\begin{tabular}{|c|c|c|}
\hline Likert's Score & Before SRM & After SRM \\
\hline 1 (never) & 7 & 1 \\
\hline 2 (rarely) & 12 & 6 \\
\hline 3 (occasionally) & 19 & 21 \\
\hline 4 (frequently) & 52 & 47 \\
\hline 5 (very frequently) & 10 & 27 \\
\hline \multicolumn{2}{|c|}{ Table 3(A). Focus in Controls (G1) } \\
\hline
\end{tabular}

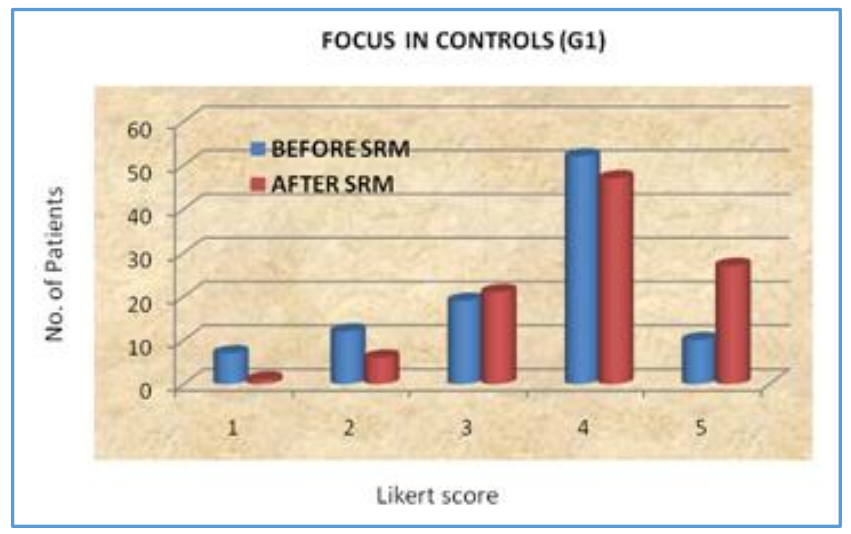

\begin{tabular}{|c|c|c|}
\hline Likert's Score & Before SRM & After SRM \\
\hline 1 (never) & 7 & 2 \\
\hline 2 (rarely) & 18 & 0 \\
\hline 3 (occasionally) & 37 & 9 \\
\hline 4 (frequently) & 25 & 50 \\
\hline 5 (very frequently) & 15 & 44 \\
\hline \multicolumn{2}{|c|}{ Table 3(B). Focus in Subjects (G2) } \\
\hline
\end{tabular}

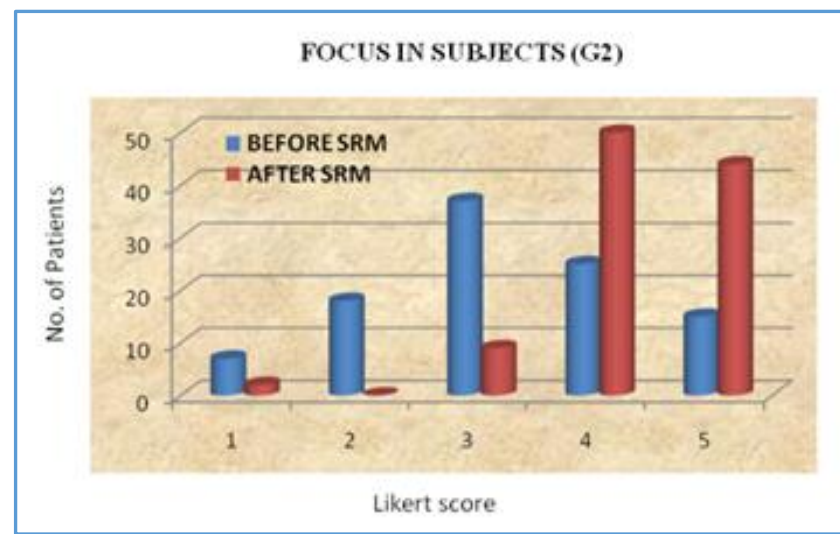

Table 4- Sleep Pattern: Controls show some improvement after using stress releasing measures. SK doers show a highly significant improvement in sleep pattern with majority having highest score on Likert's, giving a significant value $(\mathrm{p}=0.04)$.

\begin{tabular}{|c|c|c|}
\hline Likert's Score & Before SRM & After SRM \\
\hline 1 (never) & 1 & 1 \\
\hline 2 (rarely) & 8 & 3 \\
\hline 3 (occasionally) & 22 & 19 \\
\hline 4 (frequently) & 44 & 36 \\
\hline 5 (very frequently) & 29 & 44 \\
\hline \multicolumn{2}{|c|}{ Table 4(A). Sleep in Controls (G1) } \\
\hline
\end{tabular}

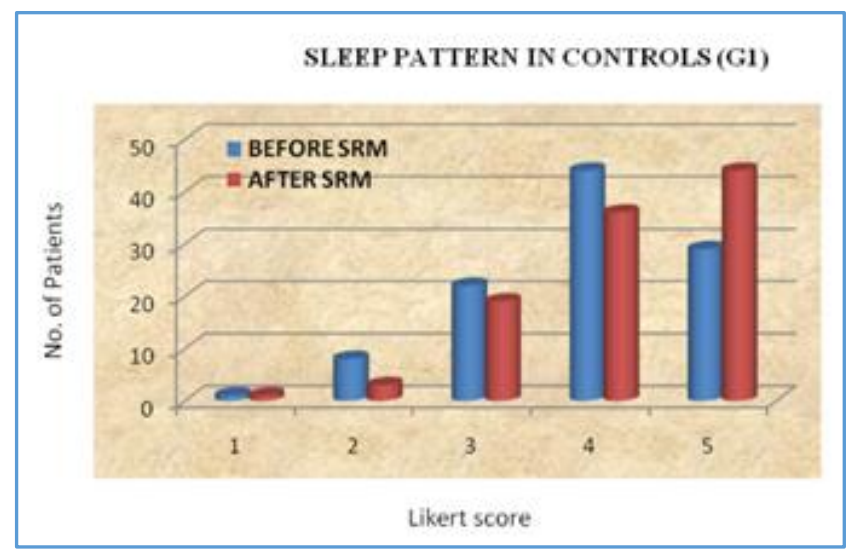




\begin{tabular}{|c|c|c|}
\hline Likert's Score & Before SRM & After SRM \\
\hline 1 (never) & 2 & 0 \\
\hline 2 (rarely) & 12 & 1 \\
\hline 3 (occasionally) & 23 & 7 \\
\hline 4 (frequently) & 37 & 39 \\
\hline 5 (very frequently) & 24 & 58 \\
\hline \multicolumn{2}{|c|}{ Table 4(B). Sleep in Subjects (G2) } \\
\hline
\end{tabular}

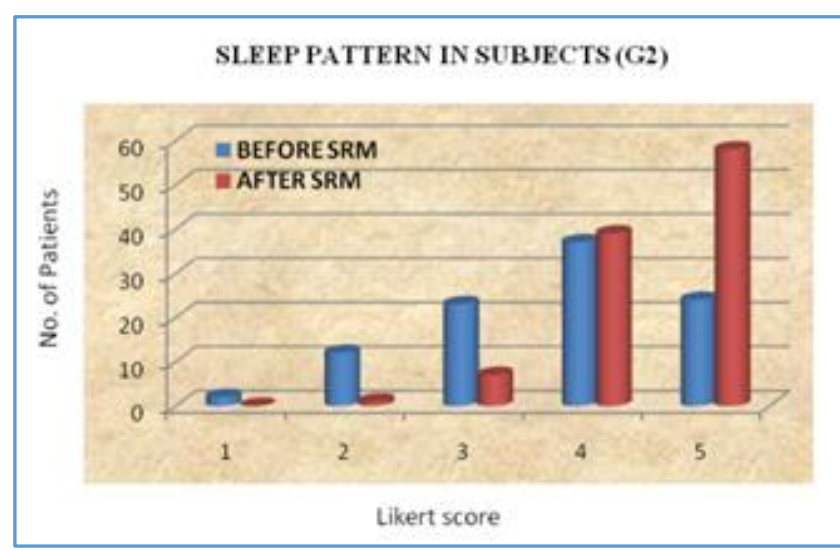

Table 5- Frustration: Although frustration was reduced in both, but SK doers give highest Likert's score $(\mathrm{p}=0.00)$.

\begin{tabular}{|c|c|c|}
\hline Likert's Score & Before SRM & After SRM \\
\hline 1 (very frequently) & 12 & 5 \\
\hline 2 (frequently) & 19 & 15 \\
\hline 3 (occasionally) & 44 & 23 \\
\hline 4 (rarely) & 21 & 36 \\
\hline 5 (never) & 8 & 20 \\
\hline \multicolumn{2}{|c|}{ Table 5(A). Frustration in Controls (G1) } \\
\hline
\end{tabular}

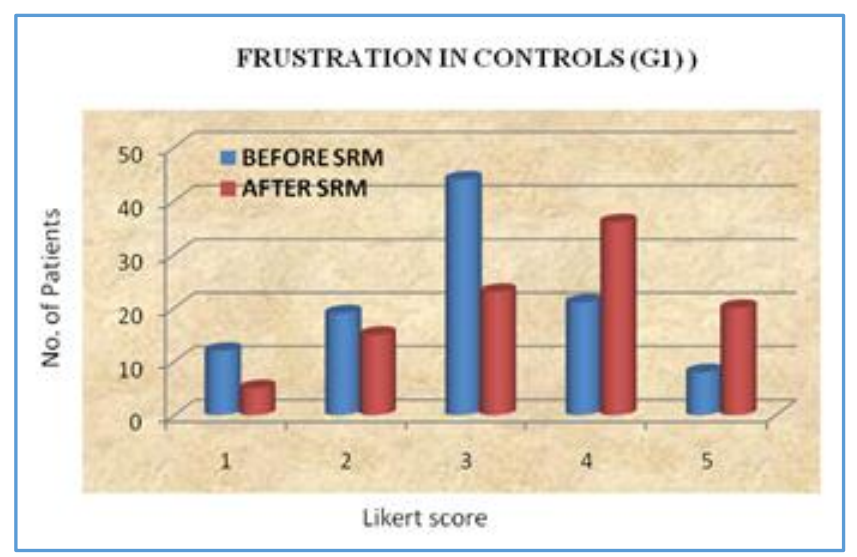

\begin{tabular}{|c|c|c|}
\hline Likert's Score & Before SRM & After SRM \\
\hline 1 (very frequently) & 6 & 2 \\
\hline 2 (frequently) & 15 & 7 \\
\hline 3 (occasionally) & 20 & 11 \\
\hline 4 (rarely) & 41 & 34 \\
\hline 5 (never) & 23 & 51 \\
\hline \multicolumn{2}{|c|}{ Table 5(B). Frustration in Subjects (G2) } \\
\hline
\end{tabular}

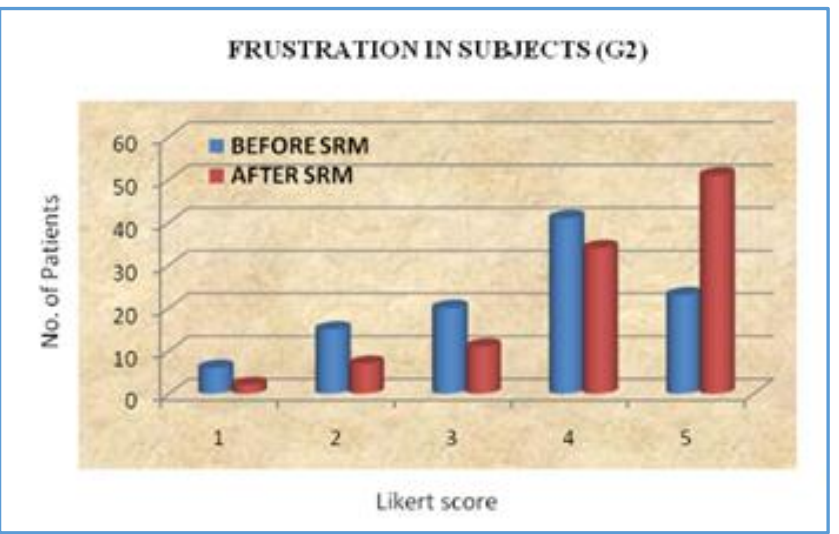

Table 6- Anger: After using relaxing methods anger has reduced in the controls, but in SK doers the scores of reduced anger are highest on Likert's scale, $(\mathrm{p}=0.005)$.

\begin{tabular}{|c|c|c|}
\hline Likert's Score & Before SRM & After SRM \\
\hline 1 (very frequently) & 6 & 5 \\
\hline 2 (frequently) & 17 & 12 \\
\hline 3 (occasionally) & 35 & 29 \\
\hline 4 (rarely) & 32 & 38 \\
\hline 5 (never) & 14 & 19 \\
\hline \multicolumn{2}{|c|}{ Table 6(A). Anger in Controls (G1) } \\
\hline
\end{tabular}

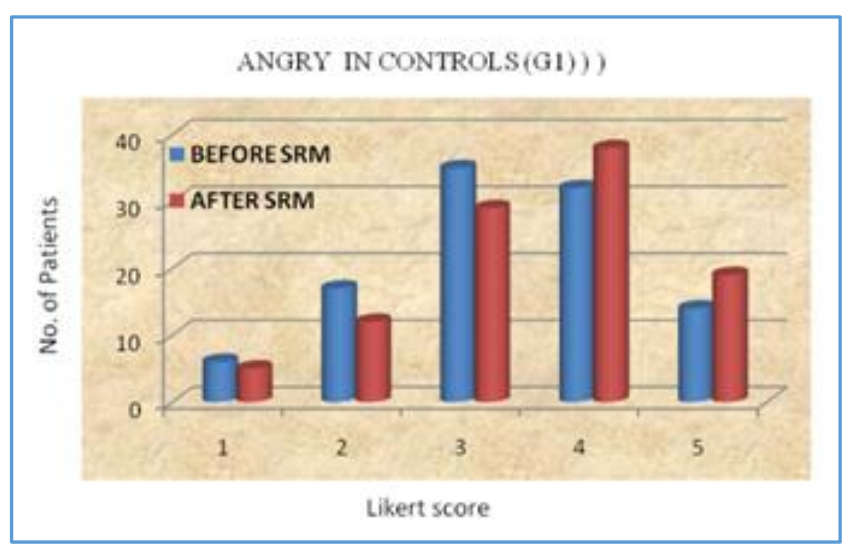

\begin{tabular}{|c|c|c|}
\hline Likert's Score & Before SRM & After SRM \\
\hline 1 (very frequently) & 5 & 1 \\
\hline 2 (frequently) & 16 & 8 \\
\hline 3 (occasionally) & 16 & 16 \\
\hline 4 (rarely) & 40 & 36 \\
\hline 5 (never) & 28 & 43 \\
\hline \multicolumn{2}{|c|}{ Table 6(B). Anger in Subjects (G2) } \\
\hline
\end{tabular}

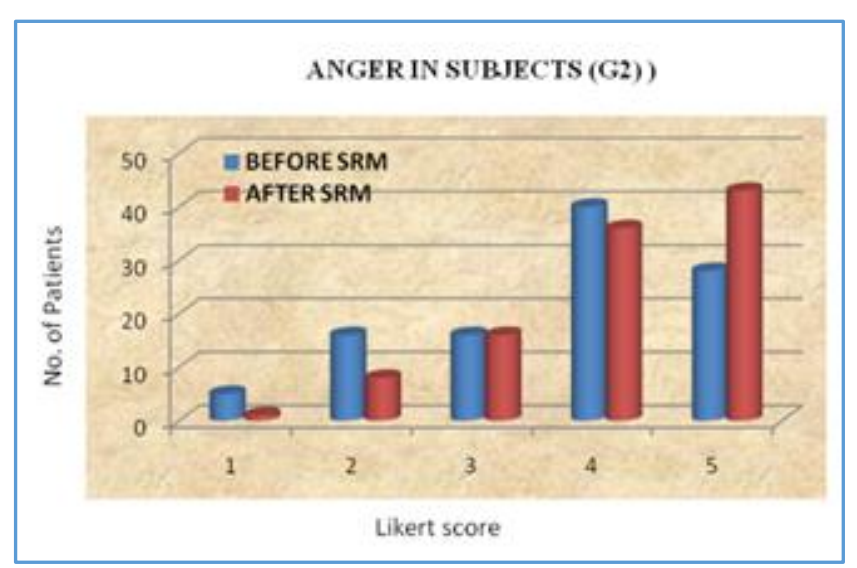


Table 7- Change in outlook: Improvement was statistically significant in SK doers, once again showing score on higher side of the Likert's scale $(\mathrm{p}=0.00)$.

\begin{tabular}{|c|c|c|}
\hline Likert's Score & Before SRM & After SRM \\
\hline $\begin{array}{c}\text { 1 (strongly } \\
\text { negative) }\end{array}$ & 2 & 2 \\
\hline $\begin{array}{c}\text { 2 (some negative } \\
\text { change) }\end{array}$ & 13 & 5 \\
\hline 3 (neutral) & 30 & 25 \\
\hline $\begin{array}{c}\text { 4 (some positive } \\
\text { change) }\end{array}$ & 38 & 50 \\
\hline 5 (strongly positive) & 21 & 20 \\
\hline \multicolumn{2}{|r|}{ Table 7(A). Change in outlook in Controls (G1) } \\
\hline
\end{tabular}

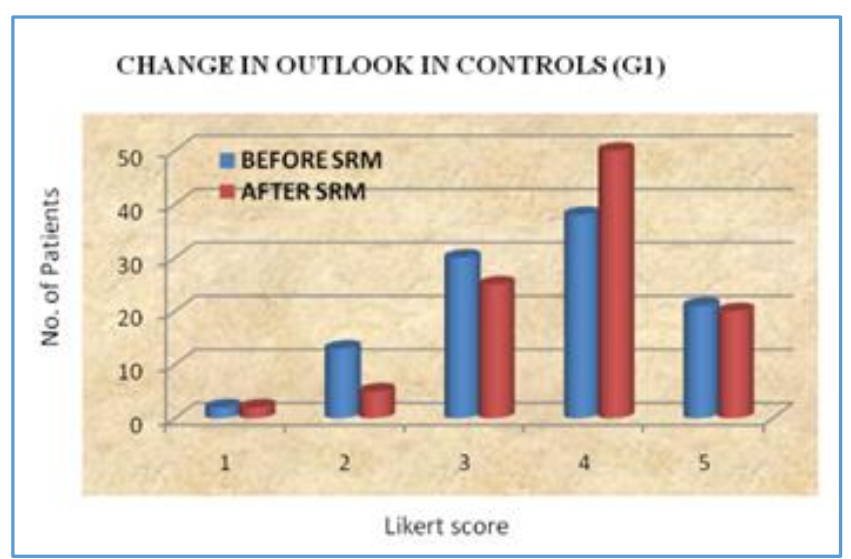

\begin{tabular}{|c|c|c|}
\hline Likert's Score & Before SRM & After SRM \\
\hline 1 (strongly negative) & 13 & 1 \\
\hline 2 (some negative change) & 17 & 2 \\
\hline 3 (neutral) & 35 & 7 \\
\hline 4 (some positive change) & 23 & 35 \\
\hline 5 (strongly positive) & 16 & 60 \\
\hline
\end{tabular}

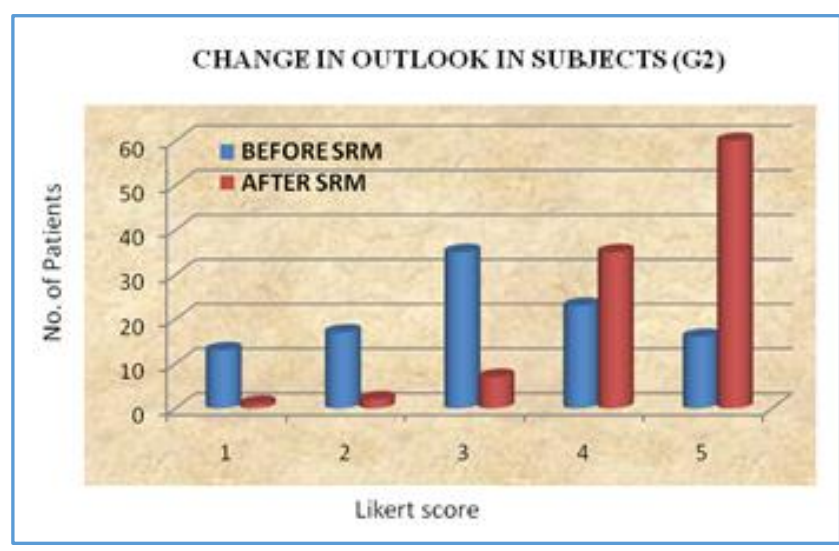

Table 8- Consumption of alcohol, tobacco, cigars: Consumption was low in both the groups.

\begin{tabular}{|c|c|c|}
\hline Likert's Score & Before SRM & After SRM \\
\hline 1 (very frequently) & 65 & 11 \\
\hline 2 (frequently) & 12 & 2 \\
\hline 3 (occasionally) & 15 & 20 \\
\hline 4 (rarely) & 8 & 28 \\
\hline 5 (never) & 2 & 26 \\
\hline \multicolumn{2}{|c|}{ Table 8(A). Consume Alcohol, Tobacco, Cigar } \\
etc. in Controls (G1) \\
\hline
\end{tabular}

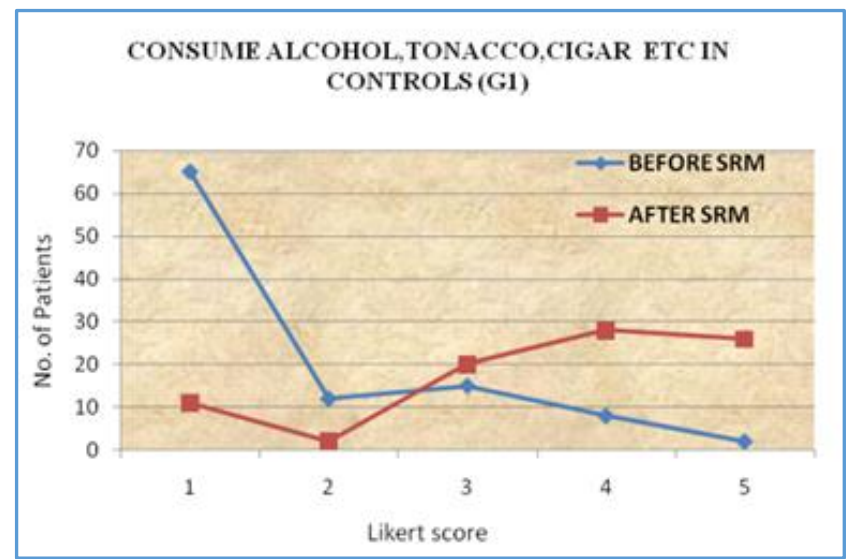

\begin{tabular}{|c|c|c|}
\hline Likert's Score & Before SRM & After SRM \\
\hline 1 (very frequently) & 82 & 2 \\
\hline 2 (frequently) & 10 & 1 \\
\hline 3 (occasionally) & 9 & 14 \\
\hline 4 (rarely) & 2 & 22 \\
\hline 5 (never) & 1 & 57 \\
\hline \multicolumn{2}{|c|}{ Table 8(B). Consume Alcohol, Tobacco, Cigar } \\
etc. in Subjects (G2) \\
\hline
\end{tabular}

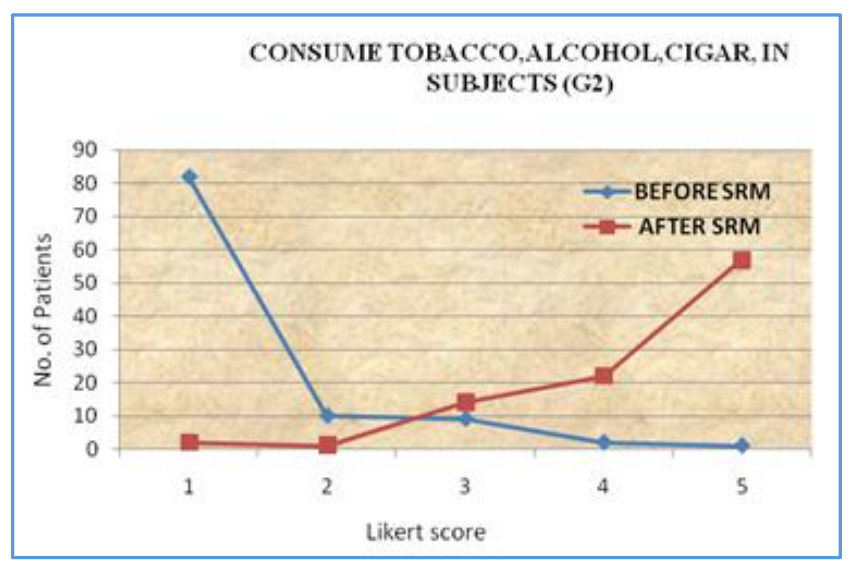

Table 9- Medical problems: Population being between 20 and 45 years, the frequency of occurrence of medical problems was less. The subjects had strongly agreed for a favourable change in health status after regular practice of SK.

\begin{tabular}{|c|c|c|}
\hline Likert's Score & Controls (G1) & Subjects (G2) \\
\hline $\begin{array}{c}\text { 1 (strongly } \\
\text { disagree) }\end{array}$ & 2 & 2 \\
\hline 2 (disagree) & 1 & 0 \\
\hline 3 (undecided) & 17 & 12 \\
\hline 4 (agree) & 30 & 31 \\
\hline 5 (strongly agree) & 25 & 48 \\
\hline \multicolumn{2}{|c|}{ Table 9. Improved Health Status in Controls (G1) } \\
compared with Subjects (G2) \\
\hline
\end{tabular}




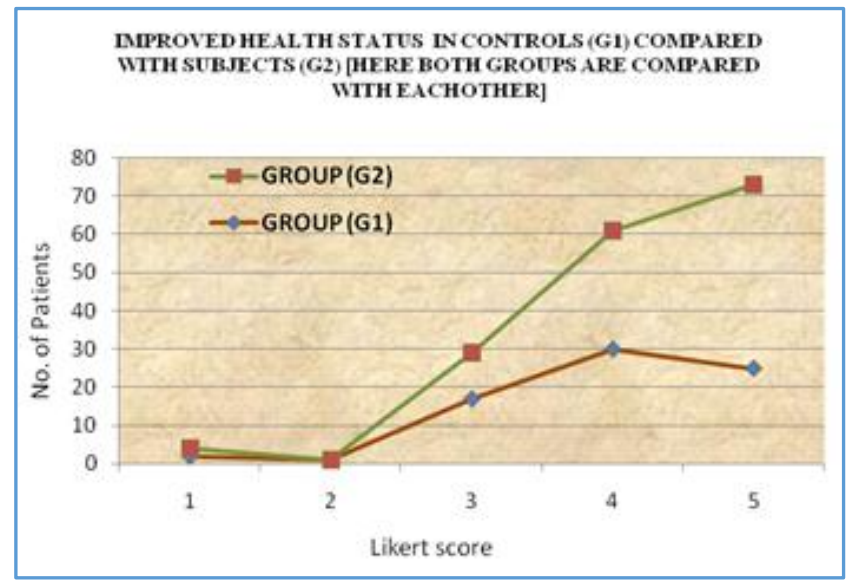

\section{DISCUSSION}

When in stress the body reacts by release of chemicals in blood. These chemicals help us to cope in different situations.

Every human being wants to be happy, whether it is money, power or materialistic possessions, all we want is for sake of happiness.

Studies have shown that those who stick themselves to long-term yoga practice report themselves to be happier and healthier. Although, you can do breathing exercises without yoga, but pairing yoga and breathing exercises together is a guaranteed happiness booster.(22)

The first and foremost fundamental responsibility for a human being is to become a joyous being. Only if you are happy can other great possibilities open up.(23)

HH Sri Sri Ravishankarji says that life is $80 \%$ joy and $20 \%$ misery, yet we hold onto $20 \%$ and make it $200 \%$. This is not a conscious act, but it just happens. Living in the moment with joy, alertness, awareness and compassion is enlightenment.(13)

In the present study, we have done both quantitative and categorical evaluation of stress parameters. Quantitatively, a significant reduction was observed (i.e. before and after change) in mean stress scores for most of the parameters in both the groups, but anger and frustration were the two parameters where the change was not found to be significant in the two groups.

However, categorical evaluation yielded significant $p$ values for all the parameters including anger and frustration as seen in Tables 5 and 6.

Categorically (Qualitatively) a significant shift towards Likert's score 5 in the SK doers ( $p=0.002)$ meant that most of the SK doers find themselves more frequently happy now.

In this study, we found that the control group attributes the cause of their unhappiness due to their jobs, business, friends etc. Thus, they depend on the improvement of the status of these factors, which are not in their control. On the other hand, the SK doers attribute the cause of unhappiness to their own-self and their outlook. These are the factors where they do not need to depend on others. They can make the necessary improvements in their own-self and make their life happier and more enthusiastic. A difference in outlook in the SK doers has made them happier now.

It was found that challenges created stress in both the groups, but controls felt it more in the present study.

SK doers seem to become somewhat more fearless and confident, thereby changing their approach towards a more positive one making themselves comparatively happier and less stressful in life.

A wavering focus is a major cause of low productivity at the work place. Yoga and pranayam are the time-tested oldest methods to improve focus. Thus, SK also enhances the brain function.(24) The regular SK doers in study have observed a heightened level of awareness and focus.

Literature shows that with SK during sleep three times more time is spent in the deep restful stage of sleep, thus giving an improved quality of sleep.(25)

Evidence shows that yoga and mindfulness (bringing one's attention to the experiences occurring in the present moment) can help improve the ability to relax, rest and get a good night's sleep. Decades ago modern medicine and science rarely considered yoga meditation as a part of health care. But in recent years experts in psychology, neuroscience, oncology and other fields have started looking into the potential benefits of these two practices, finding tangible evidence of sleep support.(26)

Stress release is an avenue by which mindfulness may support sleep. It can be developed through the practice of meditation and other training.

Frustration has also reduced significantly in regular SK doers in this study.

Stress management and moves to relieve stressful working conditions should be an integral part of any smoking/ drinking cessation programs.(27)

A literature browse also shows significant reduction in addictive behaviour after SK.(28-30)

Although consumption of alcohol, tobacco and cigar was low in both the groups, a uniform distribution of improvement is seen in controls. In subjects doing regular SK, a sharp rise in the number of people showing improved scores strongly suggests a good control on such habits, as is also indicated by a significant $\mathrm{p}$-value $(\mathrm{p}=0.00)$ for Pearson's Chi-square $(\mathrm{df}=5)=22.92$ obtained here. Thus, early and timely intervention of SRM or SK to reduce stress can prevent habituation of alcohol and smoking.

A study on a larger number of people with consistency in such habits would be required before we can declare that SK can be a means to improve our self-control and enlighten our consciousness to keep us aware and aloof of the unwanted or harmful habits.

Studies have shown that brain GABA levels spike after 1 hour of yoga. High GABA levels are associated with low levels of depression and anxiety. (22)

"Psychiatry today on Sudarshan Kriya" (Oct. 05) states in 'a breath of relief for hurricane Katrina refugees' that stress reducing programmes of SK relieved trauma symptoms perhaps by stimulating the vagus nerve.(31)

Brown Richard found that there is a sufficient evidence to consider SK to be beneficial, low risk, low cost adjunct to treatment of stress, anxiety, depression, substance abuse and rehabilitation of criminal offenders.

The fact that subjects had strongly agreed of an improved health status after a regular practice of SK is confirmed by the higher scores they show on the Likert's scale.

\section{Summary}

In a selected urban population where adults in both groups faced equal challenges in life creating an equal impact of stress, although the controls have shown a definite 
improvement in the quality of life after using stress releasing measures. But the study group clearly shows that controls feel more stressed than SK doers (p was significant at 0.02). The regular SK doers are more confident, fearless and focussed with a positive outlook. SK doers significantly surpassed the control group by scoring highest on Likert's scale in almost every parameter studied, eg. levels of happiness, focus, sleep patterns, anger, frustration, outlook, habits of consuming alcohol, gutka, tobacco and even medical problems. Thus, life appears eased out in regular kriya doers.

\section{CONCLUSION}

SK relieves stress in general population in a very significant manner when compared to other Stress Releasing Measures. SK has an extremely positive effect on physical and mental health of the general population. It can definitely be recommended as a highly beneficial, no risk, low cost option to take care of stress and its harmful effects on the human body.

\section{Limitation}

Evidence on effect of Sudarshan Kriya could have been best established if the study had been done by a Randomised Control Trial (RCT). Hence, study should be replicated on a larger, community-based sample to learn more about the effectiveness of Sudarshan Kriya in general population.

\section{Implication}

When compared with other means of stress release, SK is the only cost-effective means to improve the quality of life to its maximum. "The Magical Sudarshan Kriya."

\section{ACKNOWLEDGEMENTS}

Special thanks to Mrs. Ranjana Channe for tabulating the data and helping ease out calculations, graphs and corrections. I sincerely acknowledge the whole-hearted cooperation of the volunteers (Shrutika Ambhore, Krishna Paldiwal, Smita Hande, Arti Roy, Renuka Patil, Rasika Patil) and faculties of the Art of Living (Vijay Kubde, Sujata Kubde, Zarna De, Naina Holay, Sunita Suri, Dr. Damayanti Walkey) who helped during the distribution and collection of the questionnaires at various Art of Living follow-up centres.

\section{REFERENCES}

[1] https://en.wikipedia.org/wiki/stress, anxiety, depression.

[2] https://www.m.webmd.boots.com, stress anxiety and irritable bowel syndrome.

[3] http://ww.asthma.org.uk, stress and anxiety as asthma triggers.

[4] Kharya C, Gupta V, Deepak KK, et al. Effect of controlled breathing exercises on the psychological status and the cardiac autonomic tone: Sudarshan Kriya and Prana Yoga. Indian J Physiol Pharmacol 2014;58(3):211-21.

[5] Katzman MA, Vermani M, Gerbarg PL, et al. A multicomponent yoga based, breath intervention program as an adjunctive treatment in patients suffering from generalised anxiety disorder with or without comorbidities. International Journal of Yoga 2012;5(1):57-65.
[6] Sharma H, Sen S, Singh A, et al. Sudarshan Kriya practitioners' exhibit better antioxidant status and lower blood lactate levels. Biological Psychology 2003;63(3):p 281-91.

[7] Janakiramaiah N, Gangadhar BN, Venkatesha NM, et al. Therapeutic efficacy of Sudarshan Kriya Yoga (SKY) in dysthymic disorder. NIMHANS J 1998;16(1):21-8.

[8] Janakiramaiah N, Gangadhar BN, Venkatesha NM, et al. Antidepressant efficacy of Sudarshan Kriya Yoga (SKY) in melancholia: a randomised comparison with electroconvulsive therapy (ECT) and imipramine. Journal of Affective Disorders 2000;57(1-3):255-9.

[9] Murthy NVPJ, Janakiramaiah N, Gangadhar BN, et al. P300 amplitude and antidepressant response to Sudarshan Kriya Yoga (SKY). Journal of Affective Disorders 1998;50(1):45-8.

[10] Kumar N, Bhatnagar S, Velpandian $\mathrm{T}$, et al. Randomized controlled trial in advanced stage breast cancer patients for the effectiveness on stress marker and pain through Sudarshan Kriya and Pranayam. Indian Journal of Palliative Care 2013;19(3):180-5.

[11] Agte VV, Tarwadi K. Sudarshan Kriya Yoga for treating type 2 diabetes: a preliminary study. Alternative and Complimentary Therapies 2004;10(4):220-2.

[12] Agte VV, Jahagirdar MU, Tarwadi KV. The effects of Sudarshan Kriya Yoga on some physiological and biochemical parameters in mild hypertensive patients. Indian J Physiol Pharmacol 2011;55(2):183-7.

[13] Subramanian S, Elango T, Malligarjunan H, et al. Role of Sudarshan Kriya and Pranayam on lipid profile and blood cell parameters during the exam stress: a randomised controlled trial. Int J Yoga 2012;5(1):21-7.

[14] Chavhan DB. The effect of Sudarshan Kriya and Bhastrika Pranayama on endurance capacity in KhoKho players. International Multidisciplinary Research Journal 2013:6(1).

[15] Sharma H, Datta P, Singh A, et al. Gene expression profiling in practitioners of Sudarshan Kriya. Journal of Psychosomatic Research 2008;64(2):213-8.

[16] Brown RP, Gerabarg PL. Sudarshan Kriya yogic breathing in the treatment of stress, anxiety and depression: part I-neuro physiologic model. The Journal of Alternative and Complimentary Medicine 2005;11(1):189-201.

[17] Brown RP and Gerabarg PL. Sudarshan Kriya yogic breathing in the treatment of stress, anxiety and depression: part II-clinical applications and guidelines. The Journal of Alternative and Complimentary medicine 2005;11(4):711-7.

[18] Surekha P, Govil S, Dash D, et al. Effects of Sudarshan Kriya on male prisoners with non-psychotic psychiatric disorders: a randomized control trial. Asian Journal of Psychiatry 2014;12:43-9.

[19] Descilo T, Vedamurtachar A, Gerbarg PL, et al. Effects of a yoga breath intervention alone and in combination with an exposure therapy for posttraumatic stress disorder and depression in survivors of the 2004 South East Asia tsunami. Acta Psychiatr Scand 2010;121(4):289-300. 
[20] Fox KC, Nijeboer S, Dixon ML, et al. Is meditation associated with altered brain structure? A systemic review and meta-analysis of morphometric neuoroimaging in meditation practitioners. Neurosci Biobehav Rev 2014;43:48-73.

[21] Smith T. The vagus nerve and the healing promise of the Sudarshan Kriya. MAY 20, 2013. www.wakingtimes.com

[22] Kogan N. How Yoga can actually make you happier? http://www.happier.com

[23] Sadhguru Jaggi Vasudev. How to be happy in life? 10 Tips to move towards joy - (Blog Home>Sadhguru> Masters Words, Nov 10, 2014) isha.sadhguru.org

[24] Bhatia M, Kumar A, Kumar N, et al. Electrophysiologic evaluation of Sudarshan Kriya: an EEG, BAER, P300 study. Indian Journal of Physiology and Pharmacology 2003;47(2):157-63.

[25] Sulekha S, Thennarasu K, Vedamurthachar A, et al. Evaluation of sleep architecture in practitioners of Sudarshan Kriya Yoga and Vipassana meditation. Sleep and Biological Rhythms 2006;4(3):207-14.
[26] The Science behind meditation, yoga and sleep. April 21, 2015. https://www.pinterest.com.pin

[27] Azagba S, Sharaf MF. The effect of job stress on smoking and alcohol consumption. Health Econ Rev 2011;1:15.

[28] Kochupillai V, Kumar P, Singh D, et al. Effect of rhythmic breathing (Sudarshan Kriya and Pranayam) on immune functions and tobacco addictions. Annals of the New York Academy of Sciences 2005;1056(1):242-52.

[29] Vedamurthachur A, Janakiranaiah N, Hegde JM, et al. Antidepressant efficacy and hormonal effects of Sudarshana Kriya Yoga (SKY) in alcohol dependant individuals. Journal of Affective Disorders 2006;94(13):249-53.

[30] Ghahremani DG, Oh EY, Dean AC, et al. Effects of youth empowerment seminar on impulsive behaviour of adolescents. Journal of Adolescent Health 2013;53(1):139-41.

[31] Gerbarg PL, Brown RP. Yoga: a breath of relief for Hurricane Katrine refugees. Current Psychiatry 2005;4(10):55-67. 